DE-FG22-94PC94211

Co-firing High Sulfur Coal with Refuse Derived Fuels
Technical Progress Report \#5

\author{
Wei-Ping Pan, John T. Riley, and William G. Lloyd \\ Materials Characterization Center \\ and \\ Department of Chemistry \\ Western Kentucky University \\ Bowling Green, KY 42101
}

November 30, 1995

\begin{abstract}
DISCLAIMER
This report was prepared as an account of work sponsored by an agency of the United States Government. Neither the United States Government nor any agency thereof, nor any of their employees, makes any warranty, express or implied, or assumes any legal liability or responsibility for the accuracy, completeness, or usefulness of any information, apparatus, product, or process disclosed, or represents that its use would not infringe privately owned rights. Reference herein to any specific commercial product, process, or service by trade name, trademark, manufacturer, or otherwise does not necessarily constitute or imply its endorsement, recommendation, or favoring by the United States Government or any agency thereof. The views and opinions of authors expressed herein do not necessarily state or reflect those of the United States Government or any agency thereof.
\end{abstract}

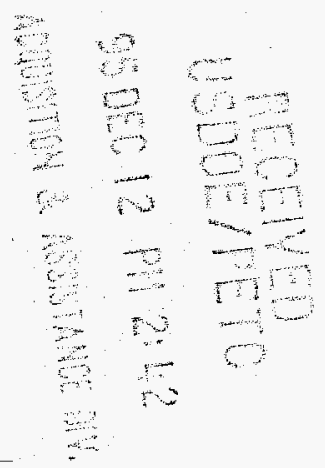

This report was prepared with the support of the U.S. Department of Energy, Grant no. DE-FG2294PC94211. However, any opinions, findings, conclusions or recommendations expressed herein are those of the authors and do not necessarily reflect the view of the DOE. US/DOE patent clearance is not required prior to the publication of this document. 


\section{Table of Contents}

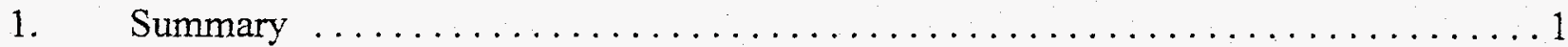

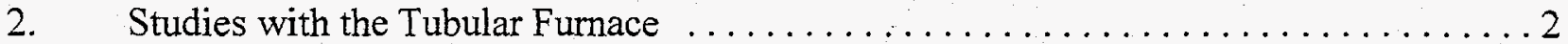

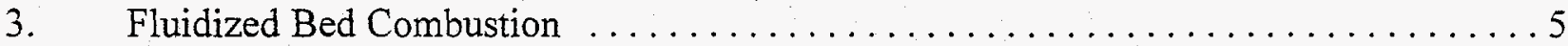

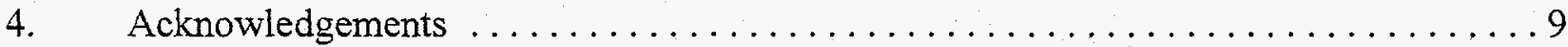

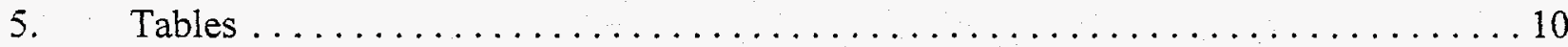

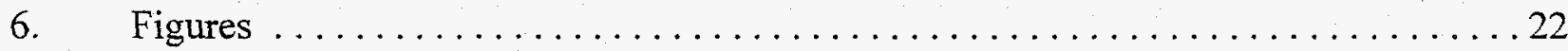

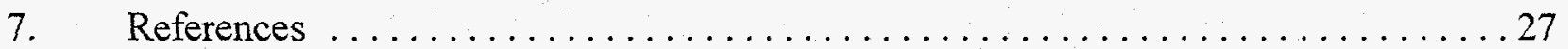




\section{Summary}

Studies involving the tubular furnace are in the process of identifying the ideal experimental coal-to-refuse derived fuel (RDF) ratio for use in the AFBC system. A series of experiments with this furnace has been performed to determine the possible chemical pathway for formation of chlorinated organic compounds during combustion of various RDF sources. Phenol and chlorine appear to be likely reactants necessary for the formation of these compounds. The main goal of these experiments is to determine the exact experimental conditions for the formation of chlorinated organic compounds, as well as methods to inhibit their development.

Work on the fluidized bed combustor has involved five combustion runs, in which a combustion efficiency of greater than $96 \%$ and with a consistent $\mathrm{CO}_{2}$ concentration of approximately $13 \%$ was obtained. Modifications responsible for these improvements include the addition of the underbed fuel feed system and revision of the flue gas sampling system. New methods of determining combustion efficiency and percentage of $\mathrm{SO}_{2}$ capture using $\mathrm{TG}$ techniques to analyze combustion products are being developed. The current outlook using this TGA/FTIR method is very promising, since previously obscured reactions are being studied. The analysis of combustion products is revealing a more complete picture of the combustion process within the AFBC system. 


\section{Studies with the Tubular Furnace}

The main focus of the continued studies with the tubular furnace is to identify the organic compounds evolved during combustion of coal with components of municipal solid waste (MSW). TG/FTIR and TG/MS studies have indicated some interaction between the components, at both the slow and fast heating rates. The results show that at a fast heating rate, the decomposition reactions are compressed into a narrow time range. Hence, the decomposition stages cannot be separated, as with the slow heating rate. The FTIR data indicate that more hydrocarbons are produced at a fast heating rate, whereas more oxidation products are obtained at the slow heating rate. Phenol was identified from the combustion of newspaper and RDF (refuse derived fuel). Mass spectrometric results indicate that molecular chlorine $\left(\mathrm{Cl}_{2}\right)$ is produced concurrently with $\mathrm{HCl}$ during the decomposition of $\mathrm{PVC}$. The ratio of $\mathrm{HCl} / \mathrm{Cl}_{2}$ is around 150. This suggests that some of the abundant $\mathrm{HCl}$ molecules may be undergoing the Thermal Deacon Reaction. This reaction is favored up to $600^{\circ} \mathrm{C}$ at atmospheric pressures. The Deacon reaction could be a plausible starting point for the formation of chlorinated dioxins from the combustion of chlorine rich fuel mixtures as is postulated below: ${ }^{1-3}$

$$
\begin{gathered}
4 \mathrm{HCl}+\mathrm{O}_{2} \rightarrow 2 \mathrm{Cl}_{2}+2 \mathrm{H}_{2} \mathrm{O} \\
\mathrm{Cl}_{2}+\text { phenol } \rightarrow \text { chlorinated phenol } \\
\text { Chlorinated phenols }- \text { PCDDs }
\end{gathered}
$$

It is difficult to identify chlorophenol using the TG/MS system for two reasons. First; the amount of phenol $(\mathrm{m} / \mathrm{z}=94)$ in the gas phase is very small. Secondly, the chlorophenol has the same parent mass, 128 , as naphthalene, and at very low levels the isotope $\mathrm{ClC}_{6} \mathrm{H}_{4} \mathrm{OH}(\mathrm{m} / \mathrm{z}=$ 130). This problem can be resolved using the tubular furnace/gas trap/GC/MS system. 
Prior to conducting any studies, the furnace was calibrated for accurate temperatures in order to reproduce reaction conditions exactly. A list of parameters which could vary (and hence effect the results) was also identified.

The raw materials, including coal 92073 (high sulfur, low chlorine), PVC, newspaper, cellulose and RDF were burned in the furnace, and the evolved gases were collected in a trap of methylene chloride cooled in an ice bath. A heating tape $\left(400^{\circ} \mathrm{C}\right)$ was wrapped around the transfer tube, where it was not in contact with the furnace, to minimize condensation.

Four grams of coal 92073 was burned in 1 standard cubic foot per hour (SCFH) of air. The furnace was preheated to a temperature of $850^{\circ} \mathrm{C}$ before the sample was introduced. The resulting gases were trapped in the chilled $\mathrm{CH}_{2} \mathrm{Cl}_{2}$. Compounds tentatively identified by $\mathrm{GC} / \mathrm{MS}$ analysis are listed in Table 2. [Tentative identification in this report means simply a match of the mass spectrum of a compound with that of a compound in the NIST mass spectra library.] Similar experiments were conducted using PVC, newspaper, cellulose and RDF. The results of the analysis are listed in Table 2 . It could be seen from the results of replicate analyses that phenol is one of the components evolved during the combustion of coal, newspaper, cellulose, and RDF. One of the major components of PVC combustion is $\mathrm{HCl}$. This is in agreement with the TG/MS results and the proposed mechanism for the formation of polychlorinated phenols. It now remains to investigate the exact ratio of coal to RDF and the experimental conditions under which they form. A sample of synthetic RDF was studied using the same conditions as that for the raw materials. The results of this study are given in Table 3. 
Studies were done on mixtures of PVC and RDF. The following three parameters were altered and their effects were investigated: (a) Ratio of PVC to RDF, (b) Temperature, and (c) Air flow (amount of oxygen). The results of this study are given in Table 4. They do not indicate any specific trend, making it difficult to draw conclusions and inferences for further study.

In parallel with the above work, a synthetic approach was used. The object here was the identification of chlorinated species formed from phenol and $\mathrm{HCl}$ and the conditions under which they survive. Phenol (100 mg) was burned in the presence of $0.5 \% \mathrm{Cl}_{2}$ in $\mathrm{N}_{2}$ and the evolved gases trapped in methylene chloride and analyzed using GC/MS. The results are summarized in Table 5. The temperature of the reaction was varied, yet the results seemed fairly consistent. It was possible to identify phenol, chlorophenol and dichlorophenol, though the absence of heating tape caused partial condensation of monochloroisomers. The same reaction performed in the solution phase seemed to occur readily at room temperature (Table $6 \mathrm{~A})$. It then remained to resolve the issue of a vapor phase or solvent phase reaction. If a reducing agent for molecular chlorine $\left(\mathrm{Cl}_{2}\right)$ is used, then the chlorine is immediately reduced on reaching the solvent, forestalling reaction in the solution phase. The reducing agent used was $\mathrm{NaHSO}_{3}$. In order to facilitate solubility of the salt, it was prepared in an acidic aqueous solution, serving a two-fold purpose: (1) reducing molecular chlorine when it comes in contact with solution and (2) reducing the solubility of chlorinated phenols (if any are formed in the vapor phase).

The resulting aqueous solution (in the gas trap) was then extracted using $10 \mathrm{~mL}$ aliquots of methylene chloride to partition aqueous and organic phases. This greatly reduced 
the possibility of reaction in aqueous phase, so it would be reasonable to conclude that the compounds identified in subsequent analyses were formed due to reaction of vapors. The results obtained are shown in Table 6B.

The focus of further studies using the tubular furnace will be to establish exact experimental conditions for the formation of these chlorinated compounds and for the possible condensation of these compounds to form dioxins (PCDDs). The exact composition of materials forming the dioxins will also be determined. It then remains to find conditions, means and techniques for reducing or preventing the formation of PCDDs and PCDFs in the AFBC (Atmospheric Fluidized Bed Combustor) system.

\section{Fluidized Bed Combustion}

Since the last quarterly report, five combustion runs have been performed in the AFBC system. The dates of these experiments were August 15, October 17, October 19, November 10, and November 30. The overall goal of these experiments has been to attain $96 \%$ combustion efficiency with a $\mathrm{CO}_{2}$ concentration of $15 \%$. Western Kentucky University coal sample \#95011 (high sulfur/low chlorine) and Kentucky limestone have been used in all experiments thus far. Experiments that are underway using the tube furnace apparatus, as discussed in the previous section, will determine the ideal experimental conditions (combination of coal and other fuels) for the burning of refuse derived fuels (RDF) with the AFBC system.

Improvements in combustion efficiency have been made with the addition of the underbed feed system, as illustrated in Figure 1. This modification, by which fuel and bed 
material is injected three inches above the setter plate, enables the mixture to be thoroughly blended with the existing combusting material. Hence, better combustion efficiency and more flexibility with air flow rates can be attained. Combustion efficiencies greater than $96 \%$ are being routinely obtained since this modification was made.

In working towards the desired $15 \% \mathrm{CO}_{2}$ concentration, a variety of problems have arisen. The foremost of these has been leakage in the flue gas sampling line, which creates a decrease in the concentration of $\mathrm{CO}_{2}$ due to increased atmospheric air intake. Finding these leaks has been difficult, since the lines only leaked significantly when placed in certain positions. For example, significant leaking might take place when changing the ion chromatograph (IC) sampling bottles. This problem has been corrected by building a platform next to the combustor and placing the GC instrument approximately 3 feet away. This has reduced the number of possible leaking connectors from eleven down to two and has reduced the length of sampling line from 80 feet down to 3 feet. During the last combustion run of November 30 , a consistent $\mathrm{CO}_{2}$ concentration of approximately $13 \%$ was attained. Although this is slightly below our desired goal, it represents the first time that consistent (Figure 2) and reliable data (FTIR spectra confirmed) were attained. Efforts during that combustion run to saturate the only possible leaking connectors with pure $\mathrm{CO}_{2}$ showed no increase in $\mathrm{CO}_{2}$ and no decrease in $\mathrm{N}_{2}$. These results provide strong evidence that no leaks are occurring. Current plans for increasing the concentration of $\mathrm{CO}_{2}$ involve: changing limestone/air/coal feed rates, reducing the bed height during combustion while maintaining constant temperature, and eliminating purge air sources (used to maintain a clear viewing window inside the combustor). 
During this reporting period the GC and FTIR equipment has also been automated so that the flue gas is analyzed precisely at preset times. This has resulted in a reduction of the number of people actually gathering and handling data, and hence, a reduction in errors.

Methods to utilize thermal analysis equipment in determining combustion efficiency are also currently being developed. This idea came from a paper presented at in 1989 at the 18th Annual NATAS Conference by S.A. Mikhail and A.M. Turcotte entitled "A TG Method of Analysis for Use in Monitoring the Efficiency of Fluidized Bed Coal Combustion Processes." This idea was modified to take advantage of our on-line TG/FTIR instruments in order to obtain a more complete picture of the combustion processes. The TG methods are capable of not only monitoring combustion efficiency, but also of determining the amount of sulfates that are absorbed by the bed material. This particular aspect is most interesting since it provides an additional way to measure the goal of $90 \%$ capture of $\mathrm{SO}_{2}$. Results from the TG technique for measuring combustion efficiency will be compared with conventional methods prior to implementation. Further investigation is underway. Fly ash from each combustion run will also be investigated using the TG/FTIR method.

The experimental conditions for analysis of bed material consist of the following six steps.

1. Heat at $20^{\circ} \mathrm{C} /$ minute to $850^{\circ} \mathrm{C}$ in $\mathrm{N}_{2}$.

2. Hold the $850^{\circ} \mathrm{C}$ temperature for 10 minutes in $\mathrm{N}_{2}$.

3. Hold the $850^{\circ} \mathrm{C}$ temperature for 10 minutes in $40 \% \mathrm{O}_{2}$ with the balance $\mathrm{N}_{2}$.

4. Hold the $850^{\circ} \mathrm{C}$ temperature for 5 minutes in $5 \% \mathrm{H}_{2}$ with the balance $\mathrm{N}_{2}$.

5. Heat $10^{\circ} \mathrm{C} /$ minute to $1000^{\circ} \mathrm{C}$ in $5 \% \mathrm{H}_{2}$ with the balance $\mathrm{N}_{2}$. 
6. Hold the $1000^{\circ} \mathrm{C}$ temperature for 20 minutes in $5 \% \mathrm{H}_{2}$ with the balance $\mathrm{N}_{2}$.

As an example, using the TG curve in Figure 3, there is a weight loss from the bed material sample that occurs at $400^{\circ} \mathrm{C}$ due to dehydroxylation of $\mathrm{Ca}(\mathrm{OH})_{2}$. Figure 4 , which is an FTIR spectrum, supports this reaction by showing the formation of $\mathrm{H}_{2} \mathrm{O}$ during this time frame. The following reaction is suggested:

$$
\mathrm{Ca}(\mathrm{OH})_{2}(\mathrm{~s}) \rightarrow \mathrm{CaO}_{(\mathrm{s})}+\mathrm{H}_{2} \mathrm{O}(\mathrm{g})
$$

More information about the reactions of the bed material can be gained by again examining the TG curve in Figure 3. Between $500^{\circ} \mathrm{C}$ and $800^{\circ} \mathrm{C}$ another significant weight loss occurs, which is mainly due to the thermal decomposition of $\mathrm{CaCO}_{3}$. This reaction is supported by the data in Figure 4, which shows the production of $\mathrm{CO}_{2}$. During step 3 another weight loss is noted, due to combustion of remaining carbon material. This evolution is likewise supported by the emission of $\mathrm{CO}_{2}$ (second peak) and $\mathrm{H}_{2} \mathrm{O}$ during this step, as shown in Figure 4. Steps 5 and 6 involve the reduction of $\mathrm{CaSO}_{4}$ to $\mathrm{CaO}$, with the suggested reaction:

$$
\mathrm{CaSO}_{4}(\mathrm{~s})+\mathrm{H}_{2}(\mathrm{~g}) \rightarrow \mathrm{CaO}(\mathrm{s})+\mathrm{SO}_{2}(\mathrm{~g})+\mathrm{H}_{2} \mathrm{O}(\mathrm{g})
$$

The curves given in Figure 4 are consistent with this reaction.

The FTIR results show the evolution of $\mathrm{SO}_{2}$ in two stages. The first one is between $600^{\circ} \mathrm{C}$ and $750^{\circ} \mathrm{C}$, and the second one is above $800^{\circ} \mathrm{C}$. This second peak is due to the reduction of $\mathrm{CaSO}_{4}$. The first smaller peak might be due to the decomposition of $\mathrm{CaSO}_{3}$.

$$
\mathrm{CaSO}_{3}(\mathrm{~s}) \rightarrow \mathrm{CaO}(\mathrm{s})+\mathrm{SO}_{2}(\mathrm{~g})
$$

Thus, the second weight loss at stage 2 is not only due to the decomposition of $\mathrm{CaCO}_{3}$, but also to the decomposition of $\mathrm{CaSO}_{3}$. Therefore, the TG/FTIR results are needed to calculate 
the amount of $\mathrm{SO}_{2}$ evolved in order to determine the amount of $\mathrm{CaSO}_{3}$ present in this stage. Further investigation is underway.

In conclusion, much time and effort is being expended to attain the goals of $96 \%$ combustion efficiency with a $15 \% \mathrm{CO}_{2}$ concentration. This principally involves:

1. Developing and utilizing techniques (TG/FTIR/MS and conventional carbon methods) which accurately measure the true combustion efficiency of the AFBC system.

2. Obtain consistent and reliable data from the flue gas sampling systems and on-line analysis systems.

\title{
4. Acknowledgements
}

We are pleased to acknowledge the valuable help of our student assistants and visiting scholars.

\author{
Undergraduates (Chemistry) \\ John Napier \\ Keith Miller \\ Jody Riley \\ Graduate students (Chemistry) \\ Richard Lu \\ Jenny Heidbrink \\ William Orndorff \\ Shobha Pururshothama \\ Xiaodong Yang
}

Visiting Scholars

Hanxu Li

Dong $\mathrm{Li}$ 
5. Tables 
Table 1. Capillary GC Parameters Set for GC/MS Analysis

Injector Temp. $\left({ }^{\circ} \mathrm{C}\right): \quad 250$

Oven Conditions:

Initial Temp. $\left({ }^{\circ} \mathrm{C}\right): \quad 100$

Initial Time $(\mathrm{min}): \quad 5$

Temp. Program: $\quad$ Rate $\left({ }^{\circ} \mathrm{C} / \mathrm{min}\right)$ Temp. $\left({ }^{\circ} \mathrm{C}\right) \quad$ Time (min)

$\begin{array}{lll}5 & 150 & 5 \\ 5 & 200 & 5 \\ 5 & 250 & 5 \\ 6 & 310 & 5\end{array}$

Equil. Time (min): $\quad 1$

Flow Controller Parameters:

Carr. Gas Press. (kPa): $\quad 106.50$

Carr.Gas Press Time (min): 5

Press. Program: Rate $(\mathrm{kPa} / \mathrm{min}) \quad$ Press $(\mathrm{kPa}) \quad$ Time $(\mathrm{min})$

$1.30 \quad 122.30 \quad 5$

$\begin{array}{lll}1.20 & 135.90 \quad 5\end{array}$

$1.30 \quad 147.50 \quad 4$

$1.20 \quad 159.10 \quad 5$

Total Flow (mL/min): $\quad 71$

Split Ratio: $\quad 32$

Interface Temp. $\left({ }^{\circ} \mathrm{C}\right): \quad 290$ 
Table 2. Tentative Identification by GC/MS of Compounds Produced

During the Combustion of Raw Coal

\section{Run 1 Coal}

Sample: $\quad 4 \mathrm{~g}$ of coal

Airflow: $\quad$ 1.0 SCFH of air

Isothermal: $\quad 850^{\circ} \mathrm{C}$ (preheated to $850^{\circ} \mathrm{C}$ )

Heating tape: 45 volts

Date: $\quad 8 / 10 / 95$

Coolant: ice

Solvent: $\quad 225 \mathrm{~mL}$ of methylene chloride

Results: $\quad$ trimethylbenzene, phenol, methyl nonane, undecane, propenylbenzene, methyl-

phenol, ethylxylene, cyclopentane, dimethylphenol, tetrahydronaphthalene,

dodecane, naphthalene, methylethylphenol, tridecane, tetradecene,

methylnaphthalene, dimethylnaphthalene, hexadecane, heptadecane, hexadecene, eicosane

Run 2 PVC

Sample: $\quad 4 \mathrm{~g}$ of PVC

Airflow: $\quad 1.0 \mathrm{SCFH}$ of air

Isothermal: $\quad 850^{\circ} \mathrm{C}$ (preheated to $850^{\circ} \mathrm{C}$ )

Heating tape: 45 volts

Date: $\quad 8 / 11 / 95$

Coolant: ice

Solvent: $\quad 225 \mathrm{~mL}$ of methylene chloride

Results: toluene, xylene, ethylbenzene, chlorobenzene, styrene, methyl-ethylbenzene, propylbenzene, trimethylbenzene, indene, methylindane, naphthalene, methylnaphthalene 
Table 2. (continued)

Run $3 \quad$ Newspaper

Sample: $\quad 4 \mathrm{~g}$ of newspaper

Airflow: $\quad 1.0 \mathrm{SCFH}$ of air

Isothermal: $\quad 850^{\circ} \mathrm{C}$ (preheated to $850^{\circ} \mathrm{C}$ )

Heating tape: 45 volts

Date: $\quad 8 / 16 / 95$

Coolant: ice

Solvent: $\quad 225 \mathrm{~mL}$ of methylene chloride

Results: toluene, furfural, furfuryl alcohol, butenol, furanone, styrene, methylcyclopentanone, 5-methyl-furfural, phenol, benzofuran, methylphenol, indene, dimethylphenol, methoxy-methylphenol

\section{Run 4 Cellulose}

Sample: $\quad 4 \mathrm{~g}$ of cellulose

Airflow: $\quad 1.0 \mathrm{SCFH}$ of air

Isothermal: $\quad 850^{\circ} \mathrm{C}$ (preheated to $850^{\circ} \mathrm{C}$ )

Heating tape: 45 volts

Date: $\quad 8 / 18 / 95$

Coolant: ice

Solvent: $\quad 225 \mathrm{~mL}$ of methylene chloride

Results: furfural, phenol, cyclohexanone, methylfuran, furanone, methylphenol, 5methylfurfural, methylphenol, furfuryl alcohol, methylundecane, dianhydroglucopyranose 
Table 3. Tentative GC/MS Identification of Compounds Evolved

During the Combustion of RDF

Sample: $\quad 4 \mathrm{~g}$ of $\mathrm{RDF}$

Airflow: $\quad 1.0 \mathrm{SCFH}$ of air

Isothermal: $\quad 850^{\circ} \mathrm{C}$ (preheated to $850^{\circ} \mathrm{C}$ )

Heating tape: 45 volts

Date: $\quad 8 / 22 / 95$

Coolant: ice

Solvent: $\quad 225 \mathrm{~mL}$ of methylene chloride

Results: toluene, acetic acid, cyclopentanone, cyclooctene, hexanal, octanal, furfural, furfuryl alcohol, furanone, styrene, cyclohexanone, 5-methylfurfural, phenol, decene, decane, methylphenol, indene, dimethylphenol, methoxy-methylphenol, dodecane, ethylmethoxyphenol, methyl-propenylphenol, hexadecene, pentadecene, pyrene, benz[a]anthracene, hexadecenol 


\section{Table 4. Tentative GC/MS Identifications from Blends}

\section{Run 6}

Sample: $\quad 2.5 \mathrm{~g}$ of coal $+2.5 \mathrm{~g}$ of PVC

Airflow: $\quad 1.0 \mathrm{SCFH}$ of air

Isothermal: $\quad 850^{\circ} \mathrm{C}$ (preheated to $850^{\circ} \mathrm{C}$ )

Heating tape: 45 volts

Date: $\quad 8 / 29 / 95$

Coolant: ice

Solvent: $\quad 225 \mathrm{~mL}$ of methylene chloride

Results: toluene, octene, octane, chlorobenzene, methylundecene, ethylbenzene, xylene, styrene, nonane, trimethylbenzene, propenylbenzene, propylbenzene, phenol, decene, methylphenol, indene, butylbenzene, methylindan, tetrahydronaphthalene, dimethylphenol, naphthalene, methylnaphthalene, biphenyl, dimethylnaphthalene, acenaphthylene, methylbiphenyl, fluorene, methylanthracene, phenylnaphthalene, pyrene, methylpyrene, benz[a]anthracene

\section{Run 7}

Sample: $\quad 2.5 \mathrm{~g}$ of PVC $+2.5 \mathrm{~g}$ of RDF

Airflow: $\quad 1.0 \mathrm{SCFH}$ of air

Isothermal: $\quad 850^{\circ} \mathrm{C}$ (preheated to $850^{\circ} \mathrm{C}$ )

Heating tape: 45 volts

Date: $\quad 9 / 04 / 95$

Coolant: ice

Solvent: $\quad 225 \mathrm{~mL}$ of methylene chloride

Results: toluene, furfural, acetic anhydride, chlorobenzene, ethylbenzene, xylene, furanone, styrene, cyclohexanone, 5-methylfurfural, benzaldehyde, propylbenzene, phenol, $\alpha$ methylstyrene, trimethylbenzene, indene, 3-methylphenol, furfuryl alcohol, decene, naphthalene, biphenyl, acenaphthylene, fluorene, anthracene, methylanthracene, octadecene, pyrene, benz[a]anthracene 


\section{Table 4. (continued)}

Run 8 Varying amount of PVC and RDF

Date: $\quad 9 / 20 / 95$

Sample: $\quad 2.5 \mathrm{~g}$ of PVC $+10.0 \mathrm{~g}$ of RDF

Airflow: $\quad 1.0 \mathrm{SCFH}$ of air

Isothermal: $\quad 850^{\circ} \mathrm{C}$ (preheated to $850^{\circ} \mathrm{C}$ )

Heating tape: 45 volts

Coolant: ice

Solvent: $\quad 225 \mathrm{~mL}$ of methylene chloride

Results: No phenols, no chlorobenzene [but see runs 7, 9-12]

Run 9 Varying air flow

Date: $\quad 9 / 27 / 95$

Sample: $\quad 2.5 \mathrm{~g}$ of PVC $+10.0 \mathrm{~g}$ of RDF

Airflow: $\quad 2.0 \mathrm{SCFH}$ of air

Isothermal: $\quad 850^{\circ} \mathrm{C}$ (preheated to $850^{\circ} \mathrm{C}$ )

Heating tape: 45 volts

Coolant: ice

Solvent: $\quad 225 \mathrm{~mL}$ of methylene chloride

Results: $\quad$ phenol, methylphenol

Run 10 Varying air flow

Date: $\quad 10 / 09 / 95$

Sample: $\quad 2.5 \mathrm{~g}$ of PVC $+10.0 \mathrm{~g}$ of $\mathrm{RDF}$

Airflow: $\quad 3.0 \mathrm{SCFH}$ of air

Isothermal: $\quad 850^{\circ} \mathrm{C}$ (preheated to $850^{\circ} \mathrm{C}$ )

Heating tape: 45 volts

Coolant: ice

Solvent: $\quad 225 \mathrm{~mL}$ of methylene chloride

Results: toluene, furfural, ethylbenzene, xylene, styrene, cumene, 5-methylfurfural, phenol, $\alpha$-methylstyrene, decene, trimethylbenzene, propylbenzene, indene, methylphenol, furanmethanol, dodecane, benzoic acid, naphthalene 
Table 4. (continued)

Run 11 Varying amount of (PVC+RDF)

Date: $\quad 10 / 13 / 95$

Sample: $\quad 2.5 \mathrm{~g}$ of $\mathrm{PVC}+5.0 \mathrm{~g}$ of $\mathrm{RDF}$

Airflow: $\quad 2.0 \mathrm{SCFH}$ of air

Isothermal: $\quad 850^{\circ} \mathrm{C}$ (preheated to $850^{\circ} \mathrm{C}$ )

Heating tape: 45 volts

Coolant: ice

Solvent: $\quad 225 \mathrm{~mL}$ of methylene chloride

Results: benzene, cyclohexene, toluene, heptene, furfural, ethylbenzene, styrene, xylene, 5methylfurfural, phenol, propylbenzene, indene, furfuyl alcohol, naphthalene, methylnaphthalene, biphenyl

Run 12 Varying combustion temperature

Date: $\quad 10 / 18 / 95$

Sample: $\quad 2.5 \mathrm{~g}$ of $\mathrm{PVC}+2.5 \mathrm{~g}$ of $\mathrm{RDF}$

Airflow: $\quad 2.0 \mathrm{SCFH}$ of air

Isothermal: $\quad 450^{\circ} \mathrm{C}$ (preheated to $450^{\circ} \mathrm{C}$ )

Heating tape: 45 volts

Coolant: ice

Solvent: $\quad 225 \mathrm{~mL}$ of methylene chloride

Results: benzene, toluene, furfural, xylene, ethylbenzene, styrene, 5-methylfurfural, phenol, methylethylbenzene, indene, furfuryl alcohol, methylheptene, naphthalene, methylnaphthalene, ethylnaphthalene 
Table 5. Study of Reactions Between Chlorine and Phenols

\section{Run 13}

Sample: $\quad 100 \mathrm{mg}$ of phenol

Date: 10/25/95

Gasflow: $\quad>65 \mathrm{~mL} / \mathrm{min}$ of $0.5 \% \mathrm{Cl}_{2}$ in $\mathrm{N}_{2}$

Isothermal: $\quad$ Room to $400^{\circ} \mathrm{C}$

Heating tape: N.A.

Coolant: N.A.

Solvent: $\quad 225 \mathrm{~mL}$ of methylene chloride

Results: phenol, $p$-chlorophenol and $o$-chlorophenol

Run 14 repeat Run 13

Sample: $\quad 100 \mathrm{mg}$ of phenol

Date: $\quad 10 / 27 / 95$

Gasflow: $\quad>65 \mathrm{~mL} / \mathrm{min}$ of $0.5 \% \mathrm{Cl}_{2}$ in $\mathrm{N}_{2}$

Isothermal: Room to $400^{\circ} \mathrm{C}$

Heating tape: N.A.

Coolant: N.A.

Solvent: $\quad 225 \mathrm{~mL}$ of methylene chloride

Results: phenol, $p$-chlorophenol, o-chlorophenol and 2,4-dichlorophenol

Run 15 Varying temperature

Sample: $\quad 100 \mathrm{mg}$ of phenol

Date: $\quad 10 / 27 / 95$

Gasflow: $\quad>65 \mathrm{mLl} / \mathrm{min}$ of $0.5 \% \mathrm{Cl}_{2}$ in $\mathrm{N}_{2}$

Isothermal: Room to $250^{\circ} \mathrm{C}$

Heating tape: N.A.

Coolant: N.A.

Solvent: $\quad 225 \mathrm{~mL}$ of methylene chloride

Results: phenol, p-chlorophenol, o-chlorophenol and 2,4-dichlorophenol 
Table 5. (continued)

Run $16 \quad$ Varying heating rate

Sample: $\quad 100 \mathrm{mg}$ of phenol

Date: $\quad 10 / 31 / 95$

Gasflow: $\quad>65 \mathrm{~mL} / \mathrm{min}$ of $0.5 \% \mathrm{Cl}_{2}$ in $\mathrm{N}_{2}$

Isothermal: $\quad 250^{\circ} \mathrm{C}$ ( preheated to $250^{\circ} \mathrm{C}$ )

Heating tape: N.A.

Coolant: N.A.

Solvent: $\quad 225 \mathrm{~mL}$ of methylene chloride

Results: 2,4-dichlorophenol

Run 17 Adding heating tape and set temperature constant

Sample: $\quad 100 \mathrm{mg}$ of phenol

Date: 10/31/95

Gasflow: $\quad>65 \mathrm{~mL} / \mathrm{min}$ of $0.5 \% \mathrm{Cl}_{2}$ in $\mathrm{N}_{2}$

Isothermal: $\quad 250^{\circ} \mathrm{C}$ ( preheated to $250^{\circ} \mathrm{C}$ )

Heating tape: 30 volts $\left(400^{\circ} \mathrm{C}\right)$

Coolant: N.A.

Solvent: $\quad 225 \mathrm{~mL}$ of methylene chloride

Results: phenol, 2,4-dichlorophenol 
Table 6. Chlorination in the Vapor and Solvent Phases

\section{(A) Not using a reducing agent}

Run 18 Determining if reaction take place in trap liquid

Sample: $\quad 100 \mathrm{mg}$ of phenol dissolved in methylene chloride

Airflow: $\quad>65 \mathrm{~mL} / \mathrm{min}$ of $0.5 \% \mathrm{Cl}_{2}$ in $\mathrm{N}_{2}$ goes through the solvent

Isothermal: Room Temperature

Heating tape: N.A.

Date: $\quad 11 / 04 / 95$

Coolant: N.A.

Solvent: $\quad 225 \mathrm{~mL}$ of methylene chloride

Results: phenol, $p$-chlorophenol, o-chlorophenol and 2,4-dichlorophenol

Run $19 \quad$ Repeat of run 18

Sample: $\quad 100 \mathrm{mg}$ of phenol

Airflow: $\quad>65 \mathrm{~mL} / \mathrm{min}$ of $0.5 \% \mathrm{Cl}_{2}$ in $\mathrm{N}_{2}$

Isothermal: $\quad 250^{\circ} \mathrm{C}$ (preheated to $250^{\circ} \mathrm{C}$ )

Heating tape: 30 volts $\left(400^{\circ} \mathrm{C}\right)$

Date: $\quad 11 / 11 / 95$

Coolant: N.A.

Solvent: $\quad 225 \mathrm{~mL}$ of methylene chloride

Results: phenol, p-chlorophenol, o-chlorophenol, and 2,4-dichlorophenol 
Table 6. (continued)

(B)

\section{Using a reducing agent $\left(\mathrm{NaHSO}_{3}\right)$}

Run 20 Trap liquid contains reagent to destroy $\mathrm{Cl}_{2}$, preventing reactions in trap

Sample: $\quad 100 \mathrm{mg}$ of phenol

Airflow: $\quad>65 \mathrm{~mL} / \mathrm{min}$ of $0.5 \% \mathrm{Cl}_{2}$ in $\mathrm{N}_{2}$

Isothermal: $250^{\circ} \mathrm{C}$ (preheated to $250^{\circ} \mathrm{C}$ )

Heating tape: 30 volts $\left(400^{\circ} \mathrm{C}\right)$

Date: $\quad 11 / 14 / 95$

Coolant: N.A.

Solvent: $\quad 2 \mathrm{~g}$ of $\mathrm{NaHSO}_{3}$ dissolved in $50 \mathrm{~mL}$ of acidified water

Extraction: Five times with $10 \mathrm{~mL}$ of methylene chloride each time.

Results: phenol, o-chlorophenol, 2,4-dichlorophenol, a trichlorophenol

Run 21 Repeat of run 20

Sample: $\quad 100 \mathrm{mg}$ of phenol

Airflow: $\quad>65 \mathrm{~mL} / \mathrm{min}$ of $0.5 \% \mathrm{Cl}_{2}$ in $\mathrm{N}_{2}$

Isothermal: $\quad 250^{\circ} \mathrm{C}$ (preheated to $250^{\circ} \mathrm{C}$ )

Heating tape: 30 volts $\left(400^{\circ} \mathrm{C}\right)$

Date: $\quad 11 / 19 / 95$

Coolant: N.A.

Solvent: $\quad 2 \mathrm{~g}$ of $\mathrm{NaHSO}_{3}$ dissolved in $50 \mathrm{~mL}$ of acidified water

Extraction: Five times with $10 \mathrm{~mL}$ of methylene chloride each time.

Results: phenol, o-chlorophenol, 2,4-dichlorophenol 
6. Figures 


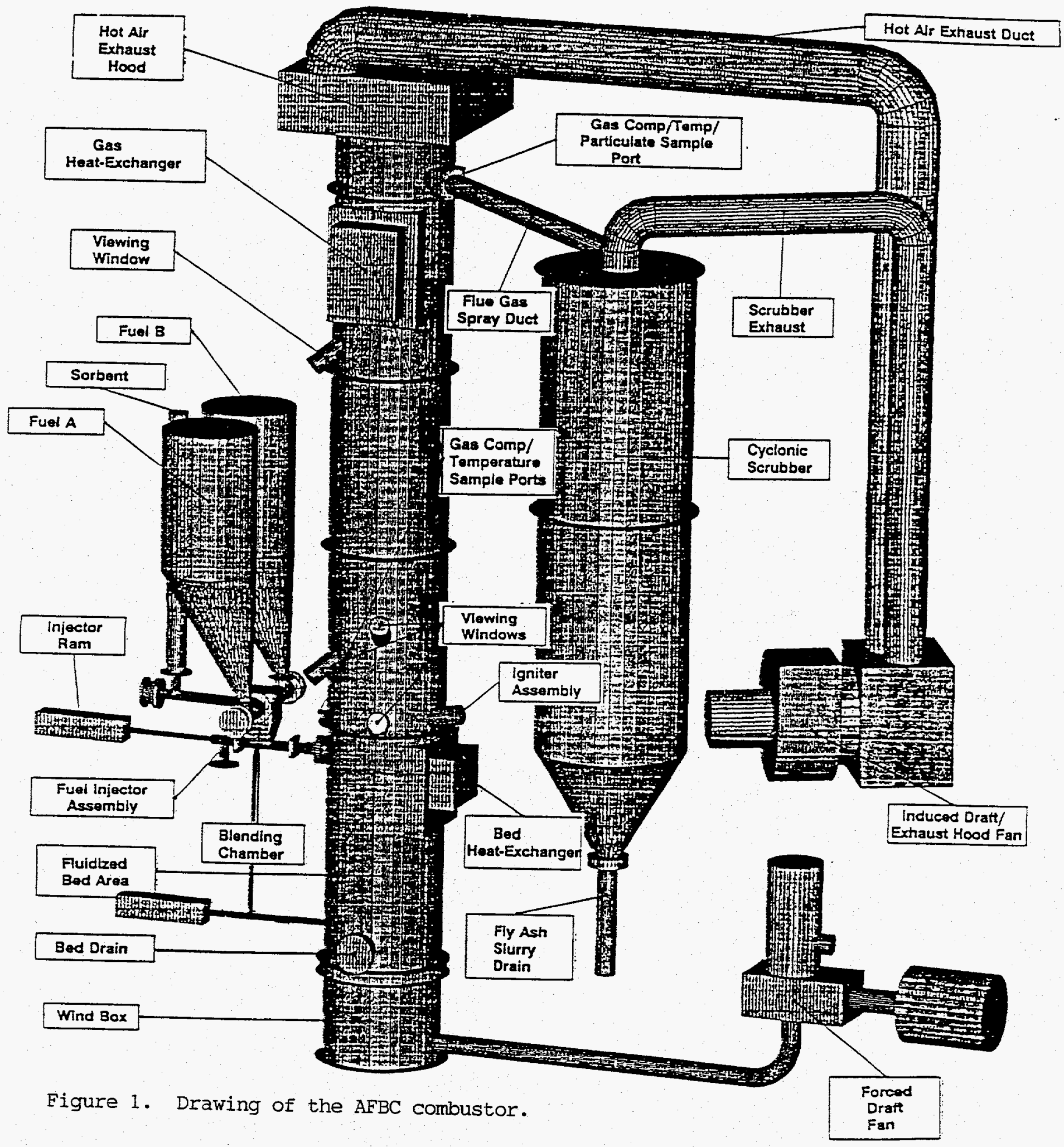




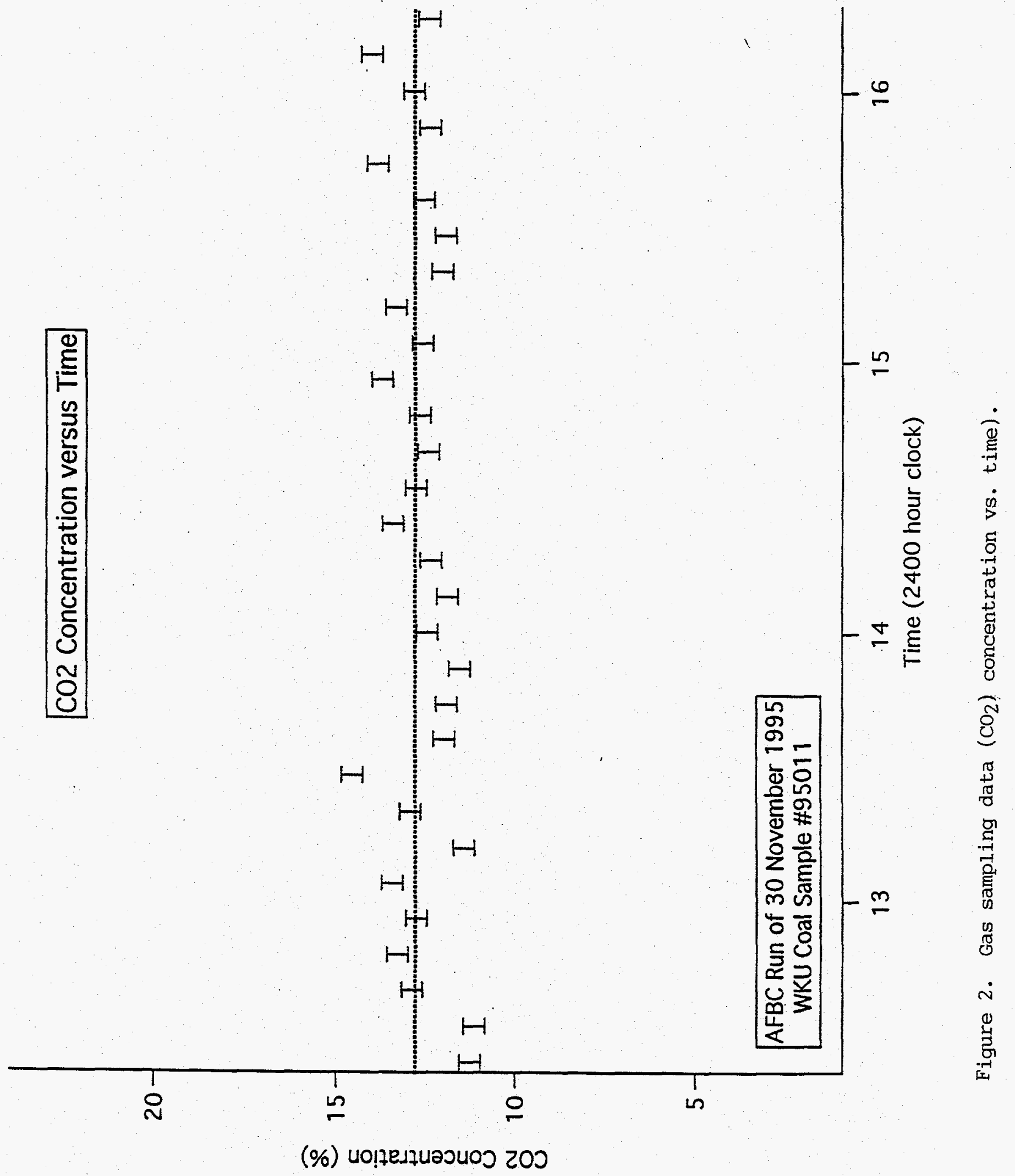




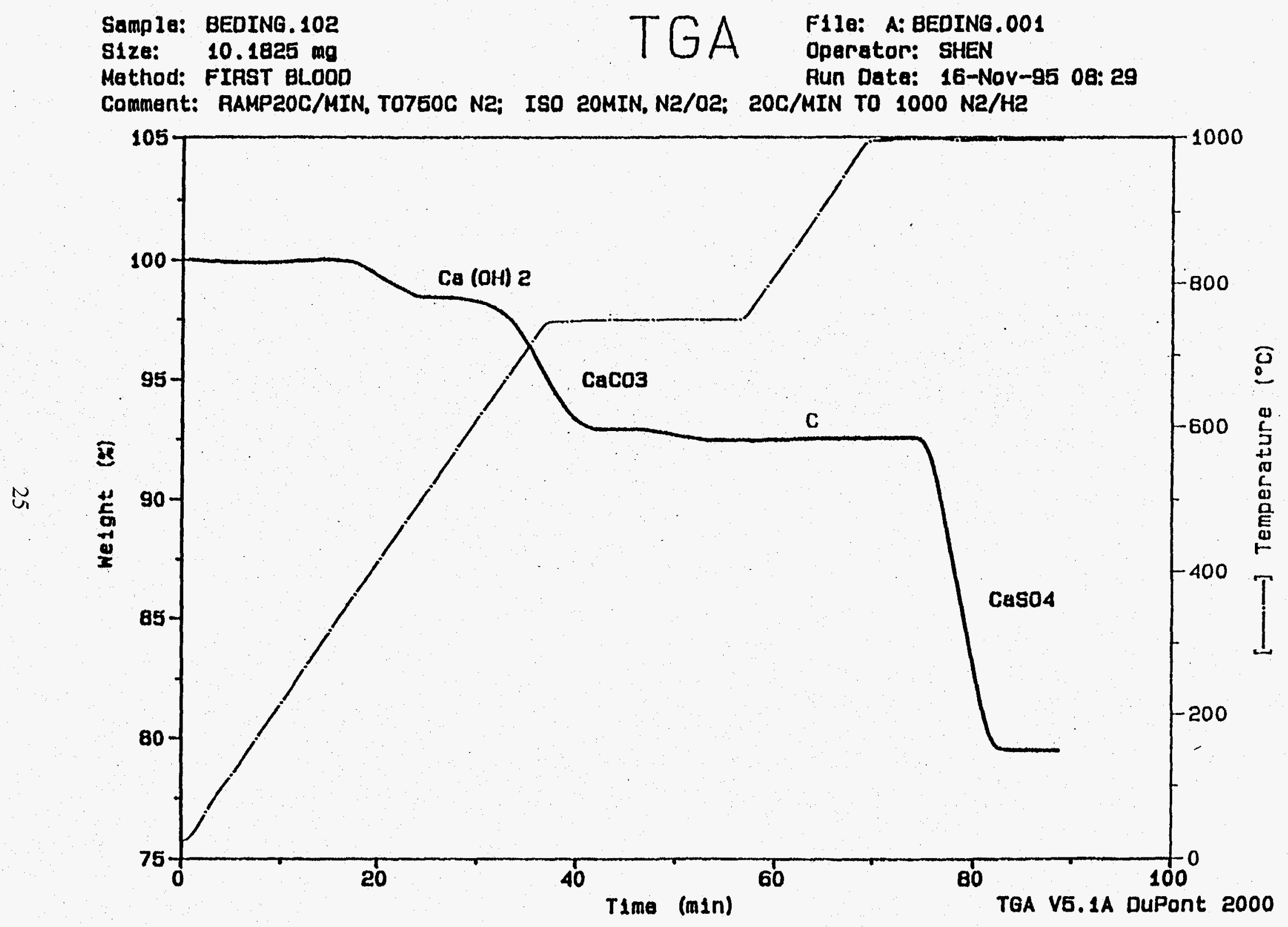

Figure 3. TG curve for bed material. 


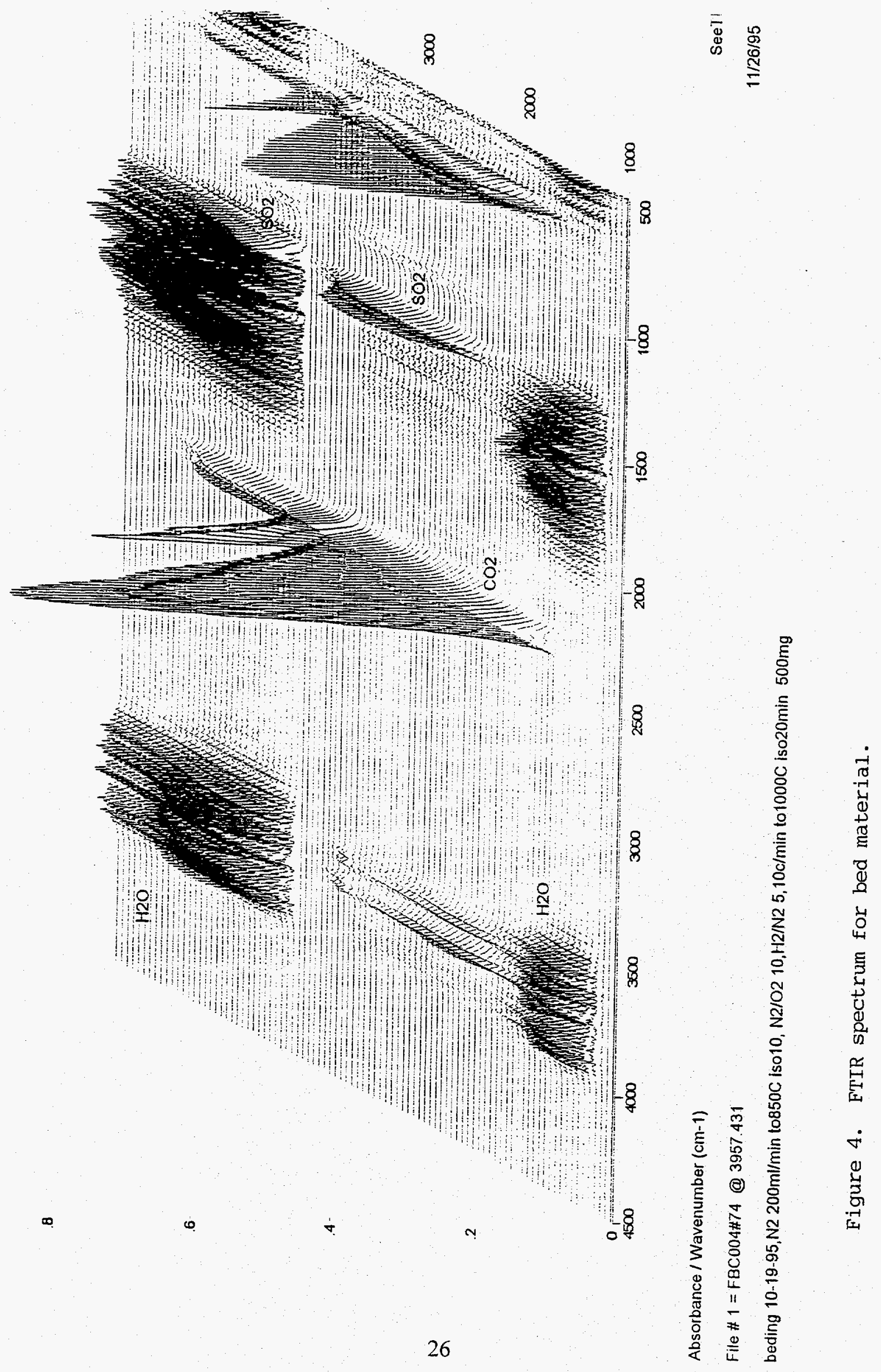




\section{References}

1. Lu, H. "A Study of the Combustion of Coal with Refuse Derived Fuels Using Thermal Analytical Techniques," Western Kentucky University, M. Sc. Thesis, 1995.

2. Lu, H.; Purushothama, S.; Hyatt, J.; Pan, W.P.; Riley, J.T.; Lloyd, W.G.; Flynn, J.; Gill, P. "Co-firing High Sulfur Coal with Refuse Derived Fuel," submitted to Thermochimica Acta for publication, November 1995.

3. Purushothama, S.; Lu, R.; Yang, X.; Hyatt, J.; Pan, W.P.; Riley, J.T.; Lloyd, W.G. "TG/MS Study of Organic Compounds Evolved During the Co-firing of Coal and Refuse Derived Fuels," to be presented at the American Chemical Society National Meeting, March 1996.

4. Mikail, S.A.; Turcotte, A.M. "A TG Method of Analysis for Use in Monitoring the Efficiency of Fluidized-Bed Coal Combustion Processes," Thermochimica Acta, 1990, $166,357-367$. 